\title{
Study on the Network Promotion Strategy of Minor Enterprises
}

\author{
Zheng Susheng \\ Scientific Research Office, Jiangxi University of Technology
}

\author{
Keywords: Minor Enterprises; Network Promotion; Promotion Strategies
}

\begin{abstract}
Minor enterprises are important parts of China's market economy bodies. For those enterprises with small scale and weak businesses, the online promotion which has low cost, wide range, long duration and good effect is certainly an unprecedented opportunity for them to develop. So how to choose proper online promotion has become the key for them to achieve successful online marketing. In the context of knowled ge economy, this paper refers to a glittering array of materials about minor enterprises' online promotion at home and abroad as well as the practice so as to summarize the successful experience of online marketing. Based on this, this paper elaborates the necessity, feasibility and inevitability for minor enterprises to adopt online promotion and carries out research and exploration on online promotion strategies.
\end{abstract}

\section{Introduction}

With the rise of information technology and e-commerce, many companies have set up their own website and started online marketing activities. There is a misconception in practice: many companies hold the idea that establishing websites is conducting informationization or carrying out e-commerce activities. In fact, building a website just helps enterprises to occupy a place for enterprises. What is more important is to help consumers find out official websites in billions of websites. Websites need to be promoted to attract customers' attention. For minor enterprises with weak ability and without famous brand, easily established website cannot help to attract visitors. Only by adopting effective and cheap online promotion can they develop their competence and change their fate from the abandoned to the beloved. Besides, based on their own characteristics and website construction objectives, minor enterprises should adopt proper online promotions to increase the visiting volume and transfer the online marketing information based on effective approaches. As a result, enterprises should be granted with more business opportunities.

\section{The necessity analysis for minor enterprises adopting online promotion}

Features of minor enterprises. Small production scale. Minor enterprises have a low level of capital stock as well as credit. Therefore, it is difficult for them to raise funds. As a result, the manufacturing scale slowly expands with weak innovative ability. What's more, their products varieties, quality, standards and technology cannot be compared with those in large scale enterprises and the production scale is relatively small.

Large number and wide range of distribution: It can be seen from the data that both in developed and developing countries, minor enterprises are dominant. By the end of the third quarter of 2013, more than 42,000,000 minor enterprises have been registered, occupying $99 \%$ of total Chinese 
enterprises. Minor enterprises have a wide management range, which almost covers every aspect of social economy and life. Besides, it is everywhere in the manufacturing, service, architecture, agriculture, transport, wholesale and retail industries.

Flexible management modes of operation: Minor enterprises invest is less with quick performance and abundant business scopes as well as a flexible management system.

In addition, minor enterprises have weak competitiveness, short life and higher ratio of bankruptcy.

The importance of online promotion for minor enterprises. Online promotion is what the time requires. Minor enterprises adopting e-commerce to promote is driven by the time. China's e-Commerce Research Center released data shows that the e-commerce market size is 7.85 trillion Yuan with a $31 \%$ year-on-year growth. Judging from that, the e-commerce industry in China has entered into an era with a rapid development speed. The E-commerce Twelve-Five plan put forwards that it is one of the important tasks to help minor enterprises to make e-commerce become popular which is an important opportunity for minor enterprises to achieve rapid development.

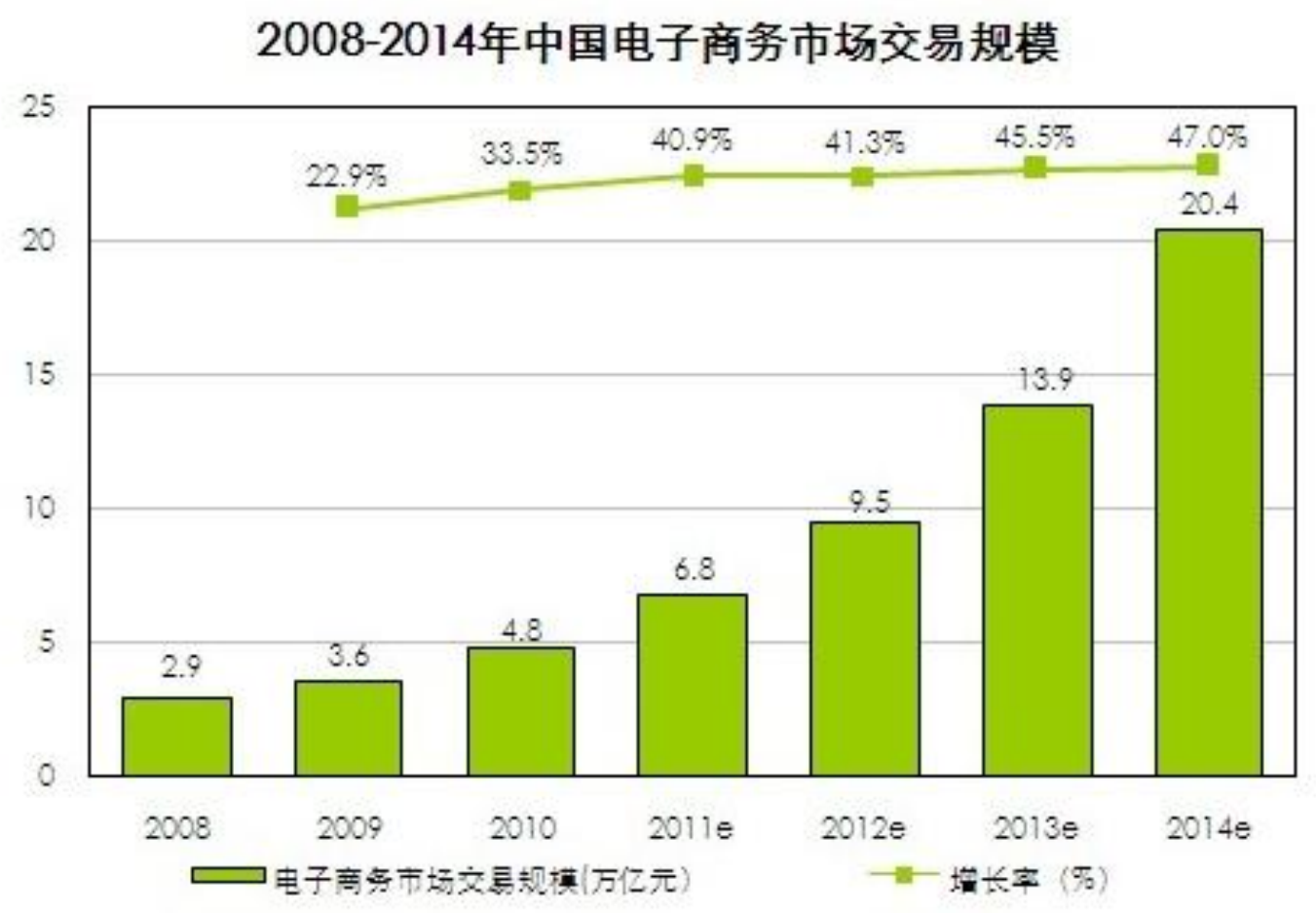

Fig. 1 Trade size of e-commerce market from 2008 to 2014

National policy support: The $17^{\text {th }}$ plenary session of Communist Party of China clearly points to develop e-commerce. The government work report of Two Session clearly points out to promote the upgrading and transferring of industries. Besides, the State of Nine Ministries jointly figures out the Twelfth Five-Year Plan and list e-commerce as the strategic emerging ind ustry. Both the central and the local places, both the coastal and the inland regions put emphasis on the development and function of e-commerce. E-commerce of China has been standing in a high position and marching toward a higher direction.

Self-development requirement of minor enterprises: Since the reform and opening up, sky rocketing multinational companies flock into China to share the Chinese market and the competition among enterprises are fierce. Chinese enterprises, especially small and medium enterprises do not have a good level of information application in terms of manufacturing process control as well as 
product structure adjustment. What's more, the marketing network is not perfect and activities adopting network are rare. Therefore, both the domestic and international resources are not taken good use of. In addition, small-business owners in some areas used to depend on traditional business model, which are located in relatively backward areas with underdeveloped market. These companies shall be greatly affected if there should be any changes in foreign market. Helping minor enterprises to full play the minor, effective and fast advantages to complete the upgrading of large scale customization, flexible production and personalization marketing are the ultimate goal and the growth path they must go through.

\section{The current condition and existing problems of minor enterprise's promoting netwo rk promotion}

The current condition of minor enterprise's promoting network promotion. On $27^{\text {th }}$ October, 2011, CNNIC released a report which is called Network Application Status of Chinese Minor Enterprises (the first half of the year of 2011) and Network Marketing for Chinese Minor Enterprises (the first half of the year of 2011). According to these reports, over 80\% minor enterprises said that they adopt network to carry out work and over $50 \%$ of them possess their own websites and online shops. What's more, over $30 \%$ minor enterprises once conducted advertising and marketing. The data proves that it is common for minor enterprises to promote based on network. From this point of view, enterprise network promotion can be regarded as one part of enterprise network marketing and minor enterprises to take the initiative to carry out it. However, it can be seen that large-scale enterprises can effectively adopt network marketing to promote products and service based on strong capital and technical strength as well as professional teams. In contrast, minor enterprises cannot compete them based on resources limitations. Besides, the problems in terms of network promotion restrict its development.

\section{Existing problems of minor enterprise's promoting network promotion}

Lack of awareness in terms of network construction. Website is the basis of network marketing and only constructing the website and network promotion can enterprises add the page view and ignite deals. Even though, some minor enterprises pay attention to network promotion, practical effect has not been improved because these enterprise websites cannot attract consumers by simple contents and limited functions. The most important point is that some websites don't set up online communication function and as a result consumers cannot timely communicate with consumers to find out those they are interested in. As a result, consumers will not purchase the products. To conclude, promotion cannot fully reflect the comprehensive meaning of network marketing.

Lack of scientific network promotion plans. Many enterprises blindly promote network promotion without proper plans. They don't make reasonable budgets, goals or evaluation of the effects so that they fall behind. Even worse, some enterprises cost much in terms of labors and finance without rewards. Therefore, making scientific network promotion plans is of crucial importance before implementing network promotion. Networking marketing plans do not only aim to promote the goals but also can examine whether the effect reach the desired objective or not.

Imprope $r$ network promotion approaches. Some websites established by minor enterprises gradually become dead-stop, which is resulted in the shortages of network promotion. For example, 
the IM promotion promoted by minor enterprises cannot help to timely respond to the question put forward by consumers so that they cannot have a good knowledge of the products or services. Finally, there should be a result of customer loss. What's more, forum promotion: if enterprises register an account in order to release a dazzling array of advertisements, the final result is to be kicked off. Besides, there are other promotion approaches. However, minor enterprises cannot fully take advantages of network networking and technology. Moreover, some enterprises totally separate network from promotion which will cause resources waste and conflicts.

\section{The implementation of minor enterprises implementing network promotion strategies}

Contents of network promotion. Before carrying out network promotion, enterprises have to figure out proper promotion programs, which is the guidance and evaluation standard. Making comprehensive solutions includes following contents: firstly, perfect enterprise website, enrich the contents to create comprehensive information and attract the attention of potential customers; secondly, collect information, analyze industry status and know which network approach to choose; thirdly, analyze the features of various promotion means and select suitable promotion approaches; fourthly, draft targeted promotion plans based on the features of different development stages; fifthly, cost controlling: enterprises have to fully play the limited resources; sixthly, focus on the effect of network promotion and make statistics on the website review.

The establishment of network promotion strategies. Every industry adopts different approaches while implementing network promotions and minor enterprises are in lack of researches on the promotion approach and concrete implementation method. Based on the features of industries, enterprises have to make corresponding programs so as to help enterprises find out the most suitable method.

The control and evaluation of network promotion. A scientific and effective network promotion strategy formation is a long-term project. After the completion of network promotion strategy, evaluation on the effect should be carried out. Even though different companies adopt different promotion approaches with different profits. In general, these approaches can be used to increase website traffic and transfer effective information to potential users in order to grant enterprises with more business opportunities. One function of network marketing is to increase website traffic. In addition, it can be found that which approach can best increase the website traffic, which approach has problems based on the data of website visitors. What's more, more valuable information can be searched. Based on this, invest more on promotion strategies and advance or cancel poor strategies. Besides, it is necessary to put new promotion strategies into practice and accept validity check. Only by repeated check and perfect promotion strategies can the promotion be improved effectively. The networking promotion directly reflects in the increasing in terms of sales. Yet, attention should be paid to one point that is to know which channels they buy their products. Based on this, check the networking promotion effect and help enterprises to improve the promotion strategies.

\section{Conclusions}

This paper analyzes the necessity and feasibility for minor enterprises to carry out network promotion based on understanding relevant theories. Based on this, this paper starts from the promotion approaches to help enterprises to find out the correct promotion means. Network 
promotion for minor promotion is not difficult to complete. Only by carefully analyzing the real condition and goals can enterprises choose correct promotion approaches and bring along with benefits. Network promotion is providing real service which also brings along with economic benefits. Therefore, it is believed that network promotion is an inevitable path for minor enterprises to carry out e-commerce activities.

\section{References}

[1]Miu Ningfang. Study on the Promotion Strategies of Chinese Minor Enterprises. Nanchang: Nanchang University. 2013.2-6.

[2]Liao Kegui. Business Condition. [J]. Discussion on the Network Promotion of Minor Enterprise, 2014(38): 176-177.

[3]Xiao Weimin. Brief Discussion on the Network Promotion of Domestic Minor Enterprises [A]. Zhang Yuxia. Economic Research Guide [C]. Harbin, 2013.10-11.

[4]Ren Shuhua. Mistake Area and Countermeasures for Enterprise Network Promotion[J]. Market Modernization, 2013 (12) : 24-26.

[5]Xiaqing. Brief Analysis on Network Promotion Policies [J]. Economist. 2013(3):63-65.

[6]The Business Edition for Modern Marketing [J]. Good Points and Disadvantages for Five Network Promotion, 2014: 45-46.

[7]Xiao Jiangguang. The Most Effective Way: the Optimization of Search Engine [J]. Time out, 2014(1):8-12.

[8]Li Yinghuo, Chang Shengjun. Problems and Suggestions for B2B Foreign Trade Network Promotion, Business Times, 2013(13 ): 54-57.

[9]Zhang Min. Trend Micro Helping Minor Enterprises Sit Back and Relax [J]. PC Week. 2014(14):15-17. 